\title{
REUSE OF COLLAGEN AND HYDROXYAPATITE FROM THE WASTE PROCESSING OF FISH TO PRODUCE POLYETHYLENE COMPOSITES
}

\author{
Túlio P. Boaventura ${ }^{\mathrm{a}, *,(1)}$, Anderson M. Peres ${ }^{\mathrm{b}}$, Viviane S. B. Gil ${ }^{\mathrm{b}}$, Camila S. B. Gil ${ }^{\mathrm{b}}$, Rodrigo L. Oréfice ${ }^{\mathrm{b}}$ and Ronald K. Luz $^{\mathrm{a}}$ \\ a'Departamento de Zootecnia, Escola de Veterinária, Universidade Federal de Minas Gerais, 31270-901 Belo Horizonte - MG, Brasil \\ bDepartamento de Engenharia Metalúrgica e de Materiais, Escola de Engenharia, Universidade Federal de Minas Gerais, 31270-901 \\ Belo Horizonte - MG, Brasil
}

Recebido em 16/07/2019; aceito em 21/11/2019; publicado na web em 10/02/2020

\begin{abstract}
In recent years, the increase in the generation of waste (e.g., bones and skin) from the processing of fish-based food related to the increase in fish consumption and the accumulation of synthetic polymers in the environment are causing major environmental concerns. Hydroxyapatite (HA) extracted from the bones and collagen from the skin of fish processing residues can be combined with synthetic polymers to maximize the use of waste material derived from fish while simultaneously reducing the use of synthetic polymers. Hence, in this study, collagen and HA were extracted from the carcasses of Lophiosilurus alexandri, and the obtained materials were reused to prepare low-density polyethylene (LDPE) blends and composites. The integrity of the triple helix structure of collagen was confirmed by FTIR and DSC showing that there was no collagen denaturation during its extraction and sample processing. The results indicated that the material produced by the incorporation of collagen into LDPE compatibilized with polyethylene-graft-maleic anhydride exhibits good mechanical and surface properties for use as a support material for ornamental articles, among other applications.
\end{abstract}

Keywords: reuse; fish; composite; artifacts.

\section{INTRODUCTION}

In recent years, the preference for healthy food has led to the increase in fish consumption worldwide. ${ }^{1}$ Fish is an excellent food as it is rich in protein with all the essential amino acids, and it is easily digested because of the absence of connective tissue. ${ }^{2}$ In 2013 , fish accounted for approximately $17 \%$ of the animal protein consumed worldwide, corresponding to approximately $6.7 \%$ of the total protein consumed. ${ }^{3}$ Fish is a rich source of vitamins, minerals, polyunsaturated fatty acids, and amino acids. Thus, fish-based food demonstrates the potential for decreasing issues associated with starvation and malnutrition in developing countries. ${ }^{4}$ However, natural fishing resources have become stagnant, which have contributed to the rapid development of aquaculture. In recent years, aquaculture has become the fastest growing animal food industry worldwide. ${ }^{5}$

The capture of wild aquatic animals has reduced to 2.5 million tons per year from 2004 to 2011. According to the Food and Agriculture Organization of the United Nations (FAO), ${ }^{3}$ the world wide consumption of fish in 2012 was approximately 158 million tons, corresponding to 66.6 million from captive production and 91.4 million from fishing. A significant amount of fish consumed is sent for industrial processing, from which a considerable amount of waste, e.g., skin, head, viscera, fins, and scales, is generated. ${ }^{6}$ The collagen and hydroxyapatite (HA) from the $\operatorname{skin}^{7}$ and bones, respectively, among these waste products, can be extracted. ${ }^{8}$

Brazil has the largest faunal diversity of freshwater fish in the world, with more than 2,500 native species, and several other species are still unknown. ${ }^{9}$ Lophiosilurus alexandri (Siluriforme: Pseudopimelodidae Steindachner, 1876), regionally known as "Pacamã," is an endemic fish species in the São Francisco River basin in Brazil. ${ }^{10}$ It is a piscivorous, sedentary fish, which typically lives in lentic environments. ${ }^{11}$ L. alexandri demonstrates immense potential for aquaculture because it is suitable for cooking; in addition, it

*e-mail: tuliopb1@ @otmail.com exhibits high commercial value because a good-quality fillet with no intramuscular bonescan weigh up to $8 \mathrm{~kg} .{ }^{12} \mathrm{Hence}$, the processing of L. alexandri generates a large amount of waste, and it can be reused with other materials for new applications in several sectors of the country economy.

Meanwhile, the overuse of synthetic polymers has raised alarming environmental concerns. ${ }^{13} \mathrm{~A}$ majority of these synthetic polymers exhibit a high molecular weight and hydrophobic characteristics, which hinder their environmental biodegradation. ${ }^{14}$ Hence, biodegradable materials obtained by mixing synthetic polymers with natural polymers ${ }^{15}$ or agricultural waste have attracted immense scientific and industrial interest. ${ }^{16,17}$ This combination maximizes the use of raw material and minimizes the accumulation of waste. ${ }^{18}$ The addition of biodegradable molecules to synthetic polymers stimulates biological attack in the matrix related to their degradation, leading to the loss of mechanical properties and increasing the contact surface of the polymer that is less affected by biochemical action. ${ }^{19}$ In this regard, some studies have reported the behavior of collagen and polyolefin mixtures for applications in medicine ${ }^{20}$ and packaging. ${ }^{21}$

In several cases, it is difficult to prepare blends and composites produced via the mixing of a synthetic polymer with a natural polymer. The low interaction between the different chemical structures in different polymers can generate materials with low mechanical properties compared to the synthetic polymers..$^{22,23}$

The blending of polymers such as polyethylene (PE), which is the most popular plastic in the world, ${ }^{24}$ and collagen leads to poor mechanical properties because of their low interaction. This issue can be resolved by the use of compatibilizers during blending ${ }^{25}$ and by the addition of HA as a reinforcing agent in polymer matrices..$^{26,27}$

In this context, this study reported the reuse of the waste generated from fish processing to produce materials that can replace parts of a synthetic polymer for applications involving PE. To this end, collagen and HA extracted from the fish carcasses of $L$. alexandri residues were combined to prepare blends and composites. In addition, the effects of collagen and HA on the mechanical properties, as well as 
the morphological, thermal, and water sorption characteristics, of the blend and composite were investigated and compared with those of pure low-density polyethylene (LDPE).

\section{MATERIALS AND METHODS}

\section{Source of carcasses}

For the experiment, fish were euthanized using $285 \mathrm{mg} \mathrm{L}^{-1}$ of a eugenol solution using procedures approved by the Ethics Committee of UFMG (CEUA Protocol 396/2012). Fish carcasses (skin and heads) were obtained from the Pacamã (L. alexandri) residues, cultivated in recirculation systems in the Larviculture Laboratory of the Federal University of Minas Gerais. After slaughter, the fish carcasses were immediately frozen until use.

\section{Hydroxyapatite extraction (HA)}

HA was extracted from the heads of the carcasses of Pacamã according to the method described by Boutinguiza et al. ${ }^{28}$ with some modifications. First, fish heads were cooked in water (1/4 ratio $(\mathrm{w} / \mathrm{v}))$ in a $5 \mathrm{~L}$ pan for more than $1 \mathrm{~h}$. Second, bones were removed and placed in an oven at $100{ }^{\circ} \mathrm{C}$ for $24 \mathrm{~h}$, followed by trituration in a knife mill (KIE model MAK 250BX) and calcination at 600 ${ }^{\circ} \mathrm{C}$ for $12 \mathrm{~h}$ at a heating rate of $20{ }^{\circ} \mathrm{C}$ per minute. Next, they were macerated using a porcelain pistil and sieved using a 400 mesh sieve, followed by dispersion in water using a cutting-edge sonicator (Branson-Digital Sonifier) in a ratio of $1 / 10(\mathrm{w} / \mathrm{v})$ with $60 \%$ power for $15 \mathrm{~min}$. Finally, the obtained dispersion was dried in an oven at $70{ }^{\circ} \mathrm{C}$ for $24 \mathrm{~h}$.

\section{Pacamã collagen extraction}

Collagen was extracted from the skin of the Pacamã carcasses according to the method described by Montedo and Gomwz-Guillen. ${ }^{29}$ First, fish skin was cut to a size of approximately $40 \mathrm{~mm} \times 40 \mathrm{~mm}$ length $\mathrm{x}$ breadth. Second, the samples were immersed in a $0.8 \mathrm{~mol} \mathrm{~L}^{-1}$ $\mathrm{NaCl}$ solution in a ratio of $1 \mathrm{~g}$ of skin to $6 \mathrm{~g}$ of solution for $10 \mathrm{~min}$. $\mathrm{Next}$, the $\mathrm{NaCl}$ solution was exchanged for a new solution, and this procedure was repeated three times. Then, the skins were washed in tap water and immersed in a $0.2 \mathrm{~mol} \mathrm{~L}^{-1} \mathrm{NaOH}$ solution in a ratio of $1 \mathrm{~g}$ of skin to $10 \mathrm{~g}$ of solution for $30 \mathrm{~min}$, and the procedure was repeated three times, followed by washing. After washing, the skins were immersed in a $0.05 \mathrm{~mol} \mathrm{~L}^{-1}$ acetic acid solution for $3 \mathrm{~h}$ in a ratio of $1 \mathrm{~g}$ of skin to $10 \mathrm{~g}$ of solution. Next, the samples were washed and immersed in deionized water at $50^{\circ} \mathrm{C}$ under stirring for $12 \mathrm{~h}$ in a ratio of $1 \mathrm{~g}$ of skin and $20 \mathrm{~g}$ of solution. The mixture was filtered, and the resulting solution was cast in polypropylene molds and maintained at $60{ }^{\circ} \mathrm{C}$ in an oven until the solvent was completely evaporated, and the collagen film was formed. Hereafter, the final product will be referred to as Pacamã collagen (PC).

\section{Material processing}

Pure LDPE (EI-1630, Quattor), LDPE/PC blend (20 wt\% PC, $4 \mathrm{wt} \%$ glycerol, and $2 \mathrm{wt} \%$ polyethylene-graft-maleic anhydride agent (PEgMA) (Sigma-Aldrich)), and the composite (20 wt $\%$ PC, $2 \mathrm{wt} \%$ PEAM, $4 \mathrm{wt} \%$ glycerol, and $5 \mathrm{wt} \% \mathrm{HA}$ ) were prepared as indicated in Table 1 . Before processing, collagen was mixed for 10 min with $20 \%$ glycerol (GLY) and $100 \%$ of water relative to the collagen mass with and without the addition of HA. The materials were processed in a polymer mixer (Thermo Haake, Poly DriveR600) at $90 \mathrm{rpm}$ and $130{ }^{\circ} \mathrm{C}$ for $5 \mathrm{~min}$, milled using a knife mill (KIE, MAK 250BX), and injected into a mold (Chen Hsong, 04470) made according to the type I standard specimen stipulated in ASTM D638-14. ${ }^{30}$

Table 1. Sample compositions

\begin{tabular}{lccccc}
\hline Sample & LDPE (\%) & PEgMA (\%) & GLY $(\%)$ & PC $(\%)$ & HA (\%) \\
\hline LDPE & 100 & - & - & - & - \\
LDPE/PC & 74 & 2 & 4 & 20 & - \\
LDPE/PC/HA & 69 & 2 & 4 & 20 & 5 \\
\hline
\end{tabular}

\section{Characterization}

$X$-ray diffraction $(X R D)$

HA extracted from fish was analyzed by XRD. XRD patterns were recorded on an EMPYREAN Philips-PA analytical diffractometer using $\mathrm{CuK} \alpha$ radiation and a monochromator. The analysis was based on the comparison of the values of the interplanar spacings and intensities of the peaks in the diffract grams of the samples and a reference sample using the PDF-2 Release 2010 database formalized by the International Centre for Diffraction Data (ICDD) and the X'PertHighscore software 2011 version.

\section{Scanning electron microscopy (SEM)}

SEM (JEOL, JSM 6360 LV) equipped with an Energy-dispersive $\mathrm{X}$-ray spectroscopy (EDX) detector was employed for microstructural analyses of the fractured surface of the samples. The fractured surfaces were obtained by immersion of the samples in liquid nitrogen for $2 \mathrm{~min}$, followed by fracture and coating with carbon.

\section{Fourier transform infrared spectroscopy (FTIR)}

FTIR absorption spectra were recorded on a Thermo Scientific Nicolet 6700 spectrometer with an Attenuated Total Reflectance (ATR) accessory. FTIR-ATR spectra were recorded from 650 to $4000 \mathrm{~cm}^{-1}$ in the absorption mode with a spectral resolution of $4 \mathrm{~cm}^{-1}$, and a total of 32 scans using a ZnSe crystal.

\section{Thermogravimetric analysis (TGA)}

TGA curves were obtained from an Exstar 7200 thermobalance (Seiko-SII Nanotechnology Inc.) under nitrogen at a heating rate of $20{ }^{\circ} \mathrm{C} \mathrm{min}-1$ and a temperature range from 25 up to $600{ }^{\circ} \mathrm{C}$.

\section{Differential scanning calorimetry (DSC)}

DSC measurements were carried out in three steps using an EXSTAR DSC/7020 apparatus under nitrogen: (1) heating the sample to $150{ }^{\circ} \mathrm{C}$, (2) cooling the sample to $-10{ }^{\circ} \mathrm{C}$, and (3) heating the sample to $150{ }^{\circ} \mathrm{C}$. The cooling and heating rates were $10{ }^{\circ} \mathrm{C} \mathrm{min}-1$. During the second heating, the melting temperature and melting heat were obtained.

\section{Mechanical characterization}

The tensile properties of the composite samples were determined using a universal tensile machine (EMIC DL3000) according to the ASTM D638-14. ${ }^{30}$ In this test, the elastic modulus (E), mechanical strength (i.e., maximum stress), and elongation at break $(\varepsilon)$ were estimated.

\section{Water absorption}

The water absorption capacity of the films was measured according to ASTM D570, ${ }^{31}$ using films with dimensions of $76.2 \mathrm{~mm}$ $\times 25.4 \mathrm{~mm}$. First, the samples were placed in an oven at $50{ }^{\circ} \mathrm{C}$ for 24 $\mathrm{h}$, cooled in a desiccator, and immediately weighed. Subsequently, 
these samples were immersed in water for a determined period and then weighed until a total of 52 days. The percentage of the water absorbed was determined from Equation 1:

$$
\text { Water absorption }[\%]=\frac{\mathrm{W}_{1}-\mathrm{W}_{0}}{\mathrm{~W}_{0}} \times 100
$$

where: $\mathrm{W}_{0}(\mathrm{~g})$ and $\mathrm{W}_{1}(\mathrm{~g})$ represent the weights of the oven-dried sample before and after immersion in water, respectively.

\section{Biodegradation test}

For the biodegradation test the samples were prepared by hot pressing of the processed material using a pressing machine heated to $130{ }^{\circ} \mathrm{C}$. The specimens were hot-pressed at 2000 PSI for $5 \mathrm{~min}$. After cooling to room temperature, the samples were cut under 1000 psi pressure using a cutting knife (EMIC AC5-32), according to the standards of ASTM D638. ${ }^{30}$ The soil biodegradation of LDPE and LDPE/PC samples was performed according to ASTM G160 for 70 days. ${ }^{32}$ Next, samples were cleaned and dried at $60{ }^{\circ} \mathrm{C}$ for $12 \mathrm{~h}$. The weight loss of the specimens was evaluated using the Equation 2.

$$
\text { Weight loss }[\%]=\frac{\mathrm{W}_{0}-\mathrm{W}_{1}}{\mathrm{~W}_{0}} \times 100
$$

where: $\mathrm{W}_{0}(\mathrm{~g})$ and $\mathrm{W}_{1}(\mathrm{~g})$ are sample weights before and after biodegradation in soil, respectively.

\section{RESULTS AND DISCUSSION}

\section{Extraction yield of hydroxyapatite and collagen}

The extraction yields of collagen and HA obtained from fish waste may vary according to the method used for extraction, type of residue, the age and species of fish. ${ }^{33}$ In the procedure utilized herein, the final extraction yields for HA and collagen were $50 \%$, relative to the total weight of the neat bone and $30 \%$, relative to the skin weight used, respectively. Antonio et al..$^{34}$ extracted collagen from the skin of different species of fish and observed that the extraction yield varied from $14.16 \%$ until $61.17 \%$, according to the fish species.
Venkatesan et al. ${ }^{35}$ utilized different calcination temperatures for the extraction of HA from Tuna bones and reported yields ranging from $57.63 \%$ to $86.8 \%$.

\section{X-ray diffraction patterns of $\mathrm{HA}$}

The XRD pattern of the extracted HA is shown in Figure 1 with the HA pattern standard from ICDD. Well-defined diffraction peaks and hexagonal-phase elements were observed in the XRD pattern of the HA extracted from the fish as also observed in the HA pattern standard. ${ }^{36}$ Intense, narrow peaks, characteristic of HA, with a large crystal size were observed. ${ }^{8}$ From the XRD pattern it is possible to affirm that the method of extracting HA from the fish carcasses of Pacamã is effective for obtaining highly crystalline HA.

\section{Photographs and morphological analysis of the obtained composites}

Figure 1S shows the photographs of the specimens from the materials processed by injection molding. As observed, pure LDPE specimens were translucent (Figure 1Sa) changing with the addition of $20 \mathrm{wt} \%$ of collagen (Figure 1Sb-c), affording a brownish color characteristic of extracted collagen. Castiello et al. ${ }^{37}$ also observed this color change for LDPE blends with hydrolyzed collagen.

The SEM images of the blends and composites showing their morphology and phase structure are shown in Figure 2. Spherical collagen-rich phases, with diameters ranging from 1 to $5 \mu \mathrm{m}$, were dispersed in the LDPE matrix (Figure 2b). Dascalu et al. ${ }^{25}$ prepared LDPE blends with hydrolyzed collagen in the presence of different compatibilizers and observed the presence of small collagen granules dispersed in the LDPE matrix. Collagen particles measuring $5 \mu \mathrm{m}$ on average were also observed in the samples containing HA and collagen (Figure 2c). The chemical elements of the particles indicated by the arrow in Figure 2c were analyzed by EDX (Figure 2f) where calcium, phosphorus, and oxygen were observed. These elements are characteristic constituents of HA as described by Venkatesan and $\operatorname{Kim} .{ }^{35}$

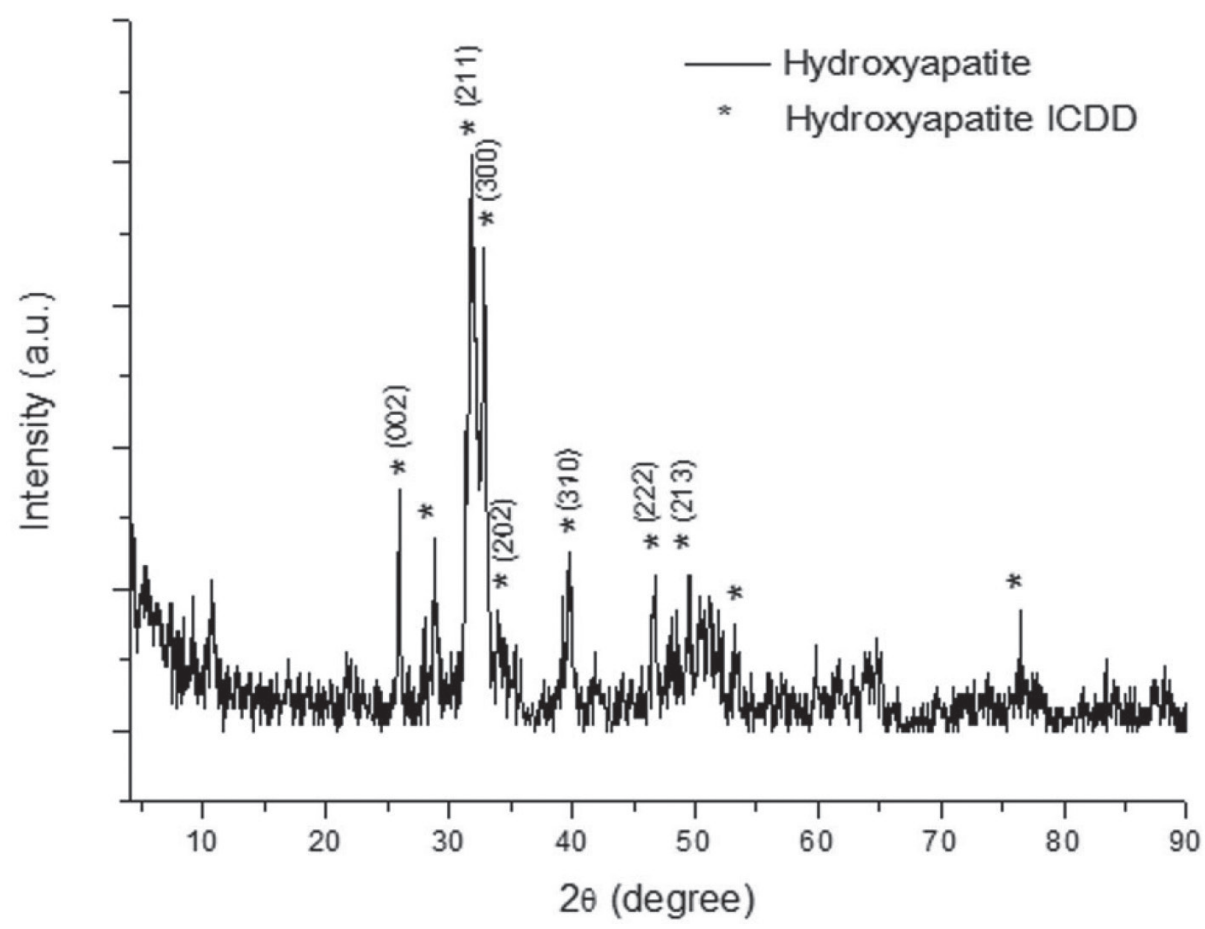

Figure 1. X-ray diffractograms of Pacamã hydroxyapatite and the hydroxyapatite standard from ICDD 

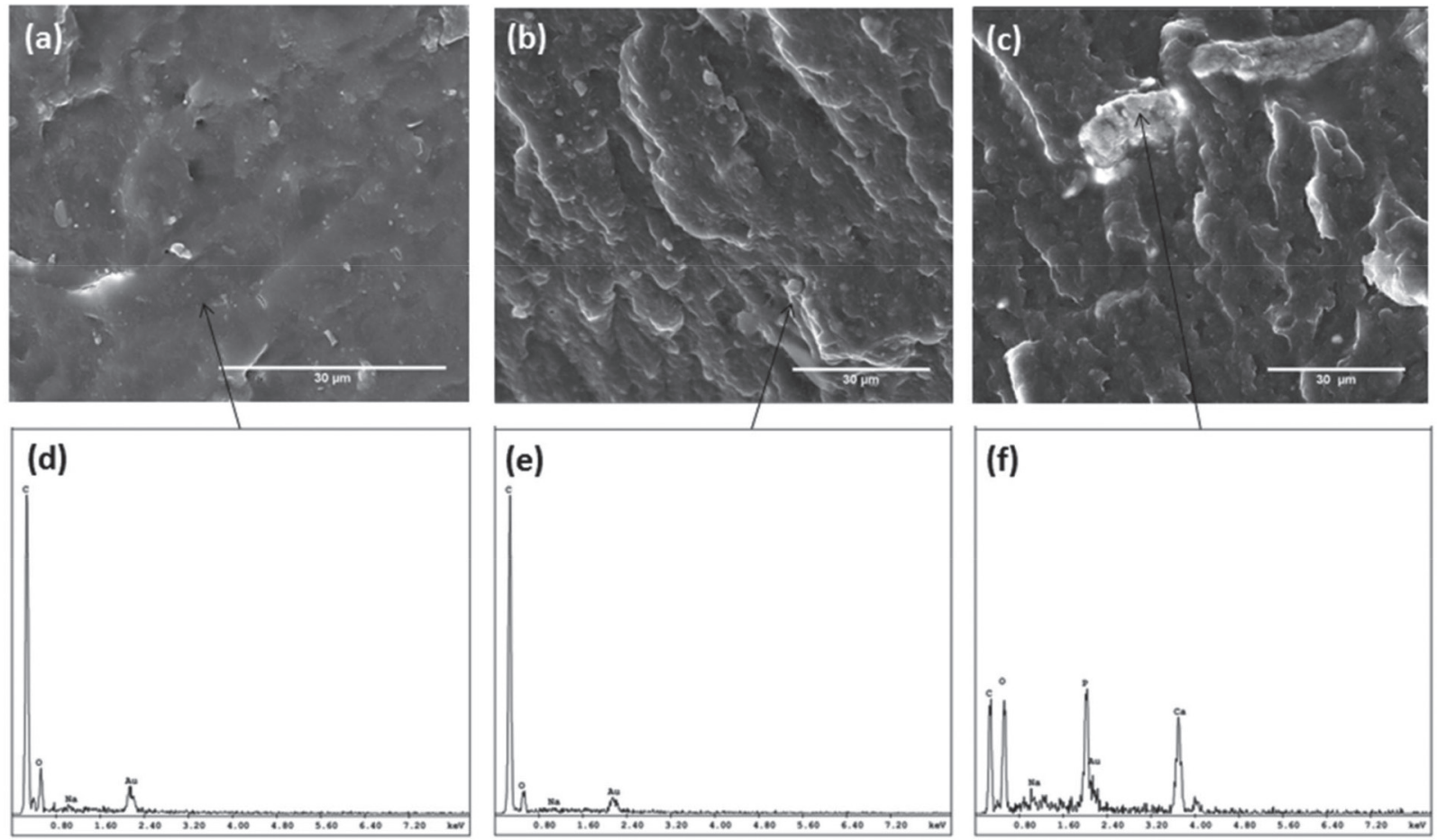

Figure 2. Scanning electron microscopy images of the sample fracture surfaces under 3000 $\times$ magnification and X-Ray (EDX) carried out on the area indicated by the arrow in images: PC $(a, d), L D P E / P C(b, e)$ and LDPE/PC/HA $(c, f)$

The SEM images indicated the migration of HA from collagen to LDPE, which may occur because of the coarse size of HA relative to the collagen-dispersed phase in the matrix.

\section{Fourier transform infrared spectroscopy (FTIR)}

Absorption bands characteristic of LDPE, i.e., C-H stretching ( 2915-2845 $\left.\mathrm{cm}^{-1}\right), \mathrm{C}-\mathrm{C}$ stretching $\left(\sim 1464 \mathrm{~cm}^{-1}\right)$, and C-C bending $\left(719 \mathrm{~cm}^{-1}\right)$, were observed in the FTIR spectrum of pure LDPE (Figure 3a). ${ }^{23,38}$ Characteristic signals for collagen, i.e., absorption bands related to amides I $\left(\sim 1629 \mathrm{~cm}^{-1}\right)$, II $\left(\sim 1540 \mathrm{~cm}^{-1}\right)$, and III $\left(\sim 1240 \mathrm{~cm}^{-1}\right)$, as well as the stretching vibration of $\mathrm{C}-\mathrm{N}$ $\left(\sim 1450 \mathrm{~cm}^{-1}\right)$, corresponding to the pyrrolidine ring in proline and hydroxyl proline, were observed in the FTIR spectrum of collagen obtained from fish skin. ${ }^{39,40}$ To verify the structural integrity of the collagen molecule, an intensity ratio of the absorption bands at $1240 / 1450 \mathrm{~cm}^{-1}$ was used. A value of 0.93 indicated that the triplehelix structure is preserved. ${ }^{39,40}$ Phosphate $(\mathrm{P}-\mathrm{O})$ bands in the range of $1145-970 \mathrm{~cm}^{-1}$ were observed for HA (Figure 3c).

The FTIR spectra of LDPE/Col and LDPE/Col/HA, Figure 3d and e, respectively, revealed overlapped absorption bands for collagen and LDPE. The addition of HA was confirmed by the presence of the absorption bands corresponding to the phosphate group in the FTIR spectrum of LDPE/Col/HA (Figure 3e).

\section{Thermogravimetric analysis (TGA)}

The extracted PC and HA thermogravimetric analysis are shown in Figure 4 curves a and b, respectively. For PC a weight loss of $10 \%$ at $110{ }^{\circ} \mathrm{C}$ corresponding to the water evaporation was observed. ${ }^{41,42}$ The thermal degradation of collagen started at around $200{ }^{\circ} \mathrm{C}$ and a total of $19 \%$ of residues were obtained at $600{ }^{\circ} \mathrm{C}$. HA exhibited thermal stability throughout the heating period (Figure 4e). ${ }^{39,40}$ The thermal behavior of pure LDPE (Figure 4c) exhibited a complete decomposition of the material at $500{ }^{\circ} \mathrm{C}$, with no trace of residues.

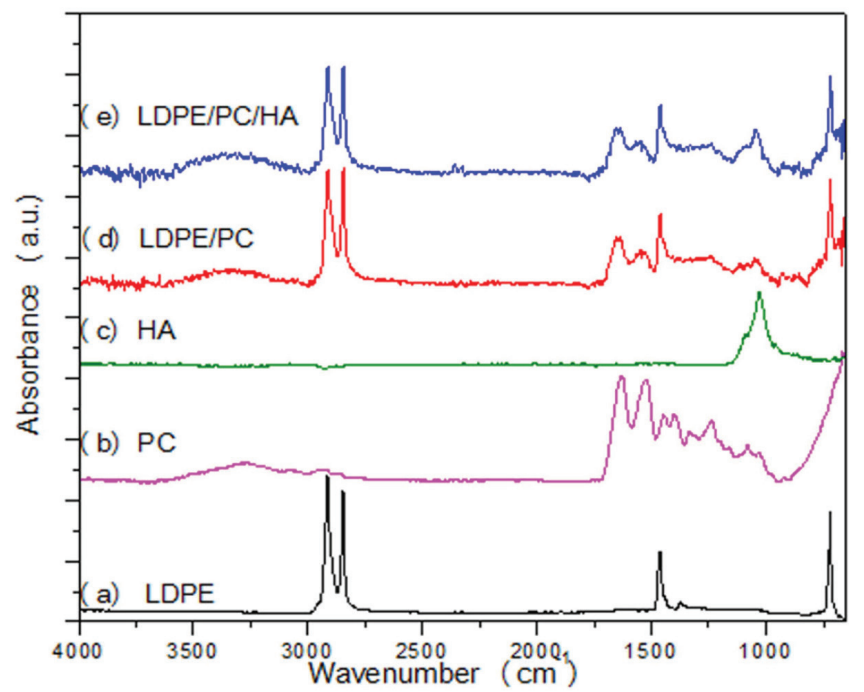

Figure 3. FTIR spectra of LDPE (a), collagen (b), HA (c), LDPE/PC (d), and LDPE/PC/HA (e)

The blend and composite TGA curves (Figure 4d,e) showed two degradation stages due to the addition of collagen into the LDPE matrix. The blend and composite degradation start at $250{ }^{\circ} \mathrm{C}$ with $80 \%$ weight loss observed at $500{ }^{\circ} \mathrm{C}$. The HA presence in the LDPE/PC/HA composite is confirmed by the increase of residues observed at $550{ }^{\circ} \mathrm{C}$ when compared with the residues content of the LDPE/PC blend.

\section{Differential scanning calorimetry (DSC)}

DSC curves for each raw and new material are shown in Figure 2S. The denaturation of proteins, like collagen, can be studied by DSC in order to verify the influence of processing conditions on the protein structure. Collagen denaturation can occur under conditions of high 


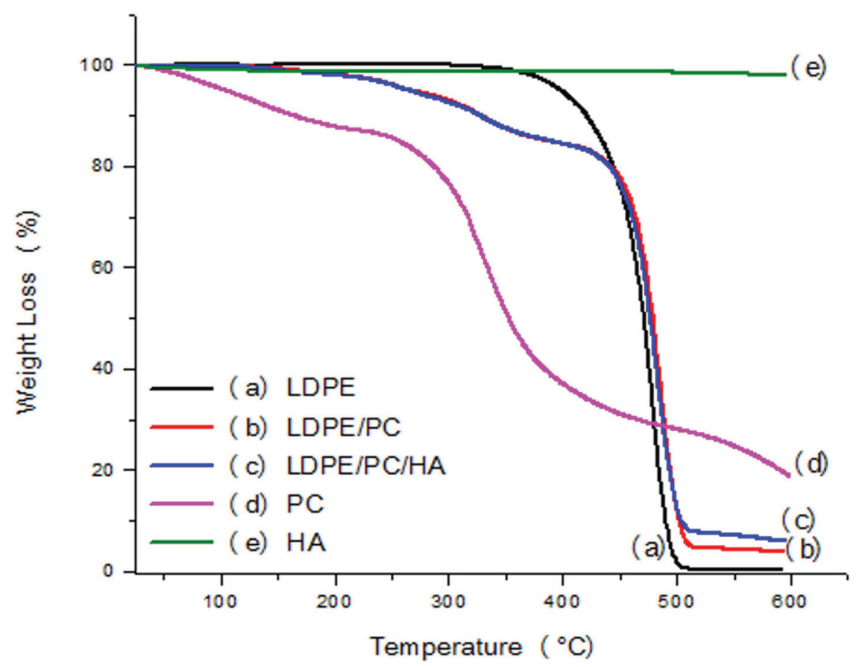

Figure 4. Thermogravimetric analysis of LDPE (a), LDPE/PC (b), LDPE/ $P C / H A(c), P C(d)$ and $H A(e)$

temperature resulting on collagen triple helix deformation into a random spiral structure forming gelatin. ${ }^{43}$ DSC curves of the obtained PC and the materials containing PC show an endothermic peak with an onset temperature of about $37.5^{\circ} \mathrm{C}$. This temperature corresponds to the denaturation temperature of collagen and the endothermic peak resulted of the heat absorbed by collagen during thermal denaturation. ${ }^{43}$ The presence of the denaturation in all DSC curves confirm that the collagen used in all the samples was not converted in gelatin during samples processing. The DSC results are in agreement with the FTIR results showing that processing conditions did not alter the native triple helix structure of collagen. Similar results were obtained by Tonhi and Plepis $^{44}$ for collagen-chitosan blends. The percentage of crystallinity (Xc) of the LDPE, LDPE/PC blends, and LDPE/PC/HA composite was calculated according to Equation 3 using DSC data:

$$
\mathrm{Xc}=\frac{\Delta \mathrm{Hm}}{\Delta \mathrm{Hm}, \mathrm{c}} \times 100
$$

where $\Delta \mathrm{H}_{\mathrm{m}}$ is the melting enthalpy measured from the DSC curves and $\Delta \mathrm{H}_{\mathrm{m}, \mathrm{c}}$ is the melting enthalpy of an ideal $100 \%$ crystalline PE sample, which is considered to be equal to $289 \mathrm{J.g}^{-1}$ for LDPE. 45

Table 2 summarizes the DSC results, including the crystallization temperatures $(\mathrm{Tc})$, melting temperatures $(\mathrm{Tm})$, melting enthalpies $(\triangle \mathrm{Hm})$, and the calculated crystallinity values for the LDPE, LDPE/PC, and LDPE/PC/HA samples and the second heating run. According to the sample analysis, Tc and Tm did not considerably change with the addition of PC and HA. The LDPE/PC blend and LDPE/PC/HA composite exhibited lower $\Delta \mathrm{Hm}$ values compared to LDPE because PE was solely responsible for crystallization. With respect to the calculated values of crystallinity, pure LDPE exhibited higher values of crystallinity compared to the blend and composite with the sole consideration of the LDPE fraction. The components of the blend and composite possibly hinder the packing capacity of the PE chains as well as crystal formation.

Table 2. Comparative DSC data for the LDPE and the LDPE/PC blends and LDPE/PC/HA composite during cooling and the second heating

\begin{tabular}{lcccc}
\hline Sample & $\operatorname{Tc}\left({ }^{\circ} \mathrm{C}\right)$ & $\operatorname{Tm}\left({ }^{\circ} \mathrm{C}\right)$ & $\Delta \mathrm{Hm}_{\left(\mathrm{Jg}^{-1}\right)}$ & $\begin{array}{c}\text { Crystallinity } \\
(\%)\end{array}$ \\
\hline LDPE & 86 & 97 & 102 & $\sim 35$ \\
LDPE/PC & 85 & 98 & 31 & $\sim 11$ \\
LDPE/PC/HA & 84 & 98 & 30 & $\sim 10$ \\
\hline
\end{tabular}

\section{Mechanical properties}

Table 3 summarizes the mechanical properties of LDPE, LDPE/PC, and LDPE/PC/HA obtained by tensile test (Figure 5). Low elongation at break values for the LDPE/PC/HA composite revealed its brittle behavior. For the LDPE/PC blend with the added $20 \%$ of collagen in PE, the tensile strength and elastic modulus were not affected, but the strain at break decreased from $153.0 \pm$ 9.0 to $75.0 \pm 11.0$ compared to pure LDPE. This observation is related to the low elongation property, characteristic of collagen. ${ }^{7}$ The content of the hydrolyzed collagen in the blend and composite and the process for the preparation of these materials can also affect the final mechanical properties. The decrease in the elongation at break for the blend and composite can also be explained by the presence of a weak interface between LDPE, PEgMA, and PC. The HA particles led to a considerable decrease in the strength of the composite compared to the blend possibly because of the size of the HA particles already shown in Figure 2, which can act as stress concentrators and because of the low degree of dispersion of these particles within the polymer matrix, leading to heterogeneities that can favor the formation and propagation of cracks. On the other hand, the observed reduction in the mechanical properties was not extremely large; hence, these new materials can still replace LDPE and other soft polymers, particularly for applications that do not require high elongation values.

Table 3. Data from the tensile tests of LDPE, LDPE/PC, and LDPE/PC/HA

\begin{tabular}{lccc}
\hline Sample & $\begin{array}{c}\text { Tensile Strength } \\
(\mathrm{MPa})\end{array}$ & $\begin{array}{c}\text { Elastic Modulus } \\
(\mathrm{MPa})\end{array}$ & $\begin{array}{c}\text { Elongation at } \\
\text { break }(\%)\end{array}$ \\
\hline LDPE & $7.7 \pm 0.4$ & $107.0 \pm 11.0$ & $153.0 \pm 9.0$ \\
LDPE/PC & $7.5 \pm 0.3$ & $128.0 \pm 25.0$ & $75.0 \pm 11.0$ \\
LDPE/PC/HA & $6.6 \pm 0.3$ & $110.0 \pm 10.0$ & $44.0 \pm 13.0$ \\
\hline
\end{tabular}

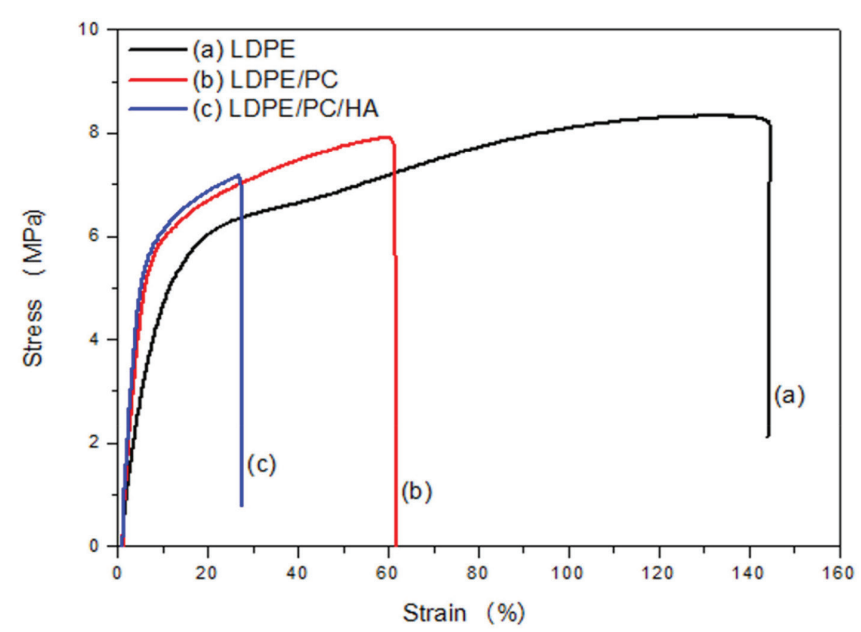

Figure 5. Stress versus strain curves for $L D P E, L D P E / P C$, and $L D P E / P C / H A$

\section{Water absorption}

The water absorption samples (Figure 6) revealed, for pure LDPE, almost no water absorption. This result is related to the hydrophobic hydrocarbon backbone present in LDPE structure. Despite this, the water absorption of the LDPE/PC blend and LDPE/PC/HA composite were slightly greater than $2 \%$ after 2 days. The water absorption capacities for the blend and composite are related to the presence of hydrophilic groups in PC. ${ }^{46}$ The water uptake for these materials achieved full saturation after 45 days with a water sorption rate of $14 \%$. 
After 27 days in water, the LDPE/PC/HA composite lost weight in water. Initially less water was observed in the blend because of the diffusion of water molecules across the sample, while in the composite, HA produced small defects in the LDPE matrix, which increased the accessibility of water molecules to the hydrophilic functional groups of the hydrolyzed collagen in the interior of the sample.

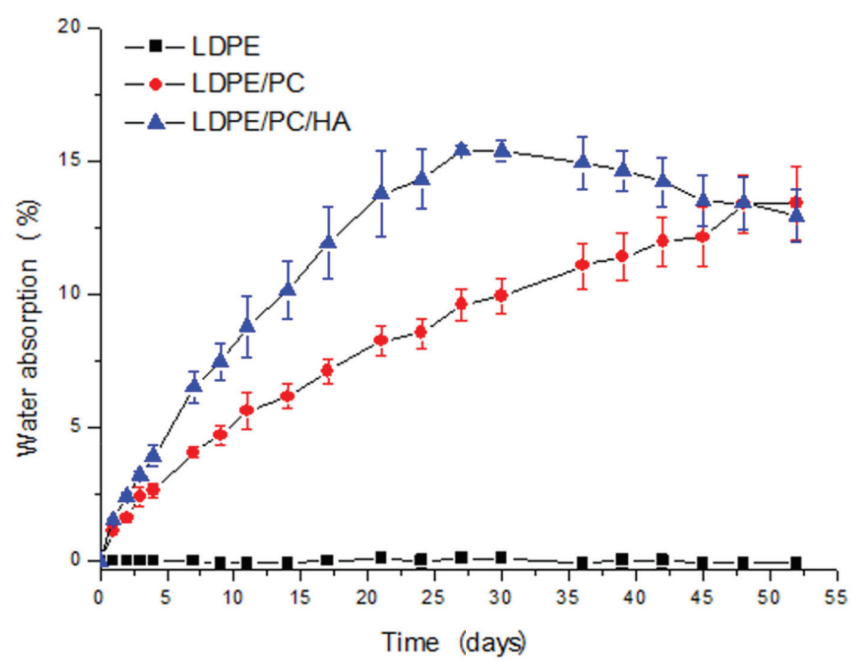

Figure 6. Water absorption versus time for $L D P E, L D P E / P C$, and $L D P E /$ $P C / H A$

\section{Biodegradation test}

The biodegradability of the samples was assessed by measuring weight loss percentage after testing, as shown in Table 4. After 70 days of exposure, LDPE showed no significant weight loss. This result may be related to the hydrophobic property of LDPE, which makes it resistant to the enzymatic attack of the microorganisms present in the soil. ${ }^{14,46}$ The weight loss obtained for LDPE/PC occurred due to the biodegradation of part of the collagen present in the material. Gelatin-based materials are susceptible to the action of protease enzymes, which are produced by various microorganisms present in the soil. ${ }^{47,48}$ Martucci and Ruseckaite ${ }^{48}$ observed almost $50 \%$ weight loss in collagen films after 7 days of exposure to soil. However, the blend of the present study, after 70 days of the biodegradation test, lost approximately $31 \%$ of its collagen mass. This loss can be justified by the difficulty of the microorganisms in attacking the collagen incorporated in the LDPE. Similar results were observed by Arcana et al. $^{49}$ studying the biodegradation of poly $(R, S)$ - $\beta$-hydroxybutyrate (PHB) and polypropylene $(\mathrm{PP})$ and observed that degradation of PHB incorporated in PP is slower than degradation of pure PHB.

Table 4. Weight loss percentage of the samples after 70 days of biodegradation test

\begin{tabular}{cc}
\hline Sample & Weight loss (\%) \\
\hline LDPE & $0.02 \pm 0.04$ \\
LDPE/PC & $6.23 \pm 0.46$ \\
\hline
\end{tabular}

\section{CONCLUSIONS}

Collagen and hydroxyapatite from Pacamã waste fish carcasses were successfully extracted. These materials were used to produce LDPE-based melt-processable polymer blends and composites using common polymer processing equipment. The hydrolyzed collagen and HA incorporated in LDPE effectively increased the hydrophilicity of the samples. The strength and elastic modulus of LDPE were not considerably affected by the presence of $20 \mathrm{wt} \%$ of collagen and HA.

The measured mechanical properties revealed that the LDPE/PC blend and LDPE/PC/HA composite can be investigated as support materials for ornamental articles, kitchenware, and plastics for agriculture. Moreover, the incorporation of these residues (collagen and HA) in PE can help in reducing the environmental impact of such byproducts derived from the fishing industry.

\section{SUPPLEMENTARY MATERIAL}

Photographs of the speciments and DSC curves of raw and new materials are freely available at http://quimicanova.sbq.org.br, in PDF format.

\section{ACKNOWLEDGMENTS}

The authors acknowledge the financial support from Conselho Nacional de Desenvolvimento Científico e Tecnológico (CNPq), Comissão Aperfeiçoamento de Pessoal de Nível Superior (CAPES), and Fundação de Amparo a Pesquisa do Estado de Minas Gerais (FAPEMIG).

\section{REFERENCES}

1. Cahu, C.; Salen, P.; de Lorgeril, M.; Nutr. Metab. Cardiovasc. Dis. 2004, $14,34$.

2. Kristinsson, H. G.; Rasco, B. A.; Crit. Rev. Food Sci. Nutr. 2000, 40, 43.

3. FAO; The state of world fisheries and aquaculture; 2016.

4. Singh, D. K.; Ranjan, A.; Nutr. Food Sci. 2016, 1.

5. Subasinghe, R.; Soto, D.; Jia, J.; Rev. Aquac. 2009, 1, 2.

6. Kim, S.-K.; Mendis, E.; Food Res. Int. 2006, 39, 383.

7. Tang, L.; Chen, S.; Su, W.; Weng, W.; Osako, K.; Tanaka, M.; Process Biochem. 2015, 50, 148.

8. Pon-On, W.; Suntornsaratoon, P.; Charoenphandhu, N.; Thongbunchoo, J.; Krishnamra, N.; Tang, I. M.; Mater. Sci. Eng., C 2016, 62, 183.

9. Ecker, F.; De Fries, L. C. C.; Ferrer., J.; Bertaco, V. A.; Luz-Agostinho, K. D. G.; Silva, J. F. P.; Cardoso, A. R.; Lucena, Z. M. S.; Lucena, C. A. S.; Braz. J. Biol 2013, 73, 79.

10. Costa, D. C.; de Souza e Silva, W.; Melillo Filho, R.; Miranda Filho, K. C.; dos Santos, J. C. E.; Kennedy Luz, R.; Anim. Reprod. Sci. 2015, 159, 148.

11. Guimarães-Cruz, R. J.; Santos, J. E.; Sato, Y.; Veloso-Júnior, V. C.; J. Appl. Ichthyol. 2009, 25, 321 .

12. Kitagawa, A. T.; Costa, L. S.; Paulino, R. R.; Luz, R. K.; Rosa, P. V.; Guerra-Santos, B.; Fortes-Silva, R.; Appl. Anim. Behav. Sci. 2015, 171, 211.

13. Angelini, L. G.; Scalabrelli, M.; Tavarini, S.; Cinelli, P.; Anguillesi, I.; Lazzeri, A.; Ind. Crops Prod. 2015, 75, 178.

14. Arutchelvi, J.; Sudhakar, M.; Arkatkar, A.; Doble, M.; Bhaduri, S.; Uppara, P. V.; Indian J. Biotechnol. 2008, 7, 9.

15. Avolio, R.; Graziano, V.; Pereira, Y. D. F.; Cocca, M.; Gentile, G.; Errico, M. E.; Ambrogi, V.; Avella, M.; Carbohydr. Polym. 2015, 133, 408.

16. Cholake, S. T.; Rajarao, R.; Henderson, P.; Rajagopal, R. R.; Sahajwalla, V.; J. Clean. Prod. 2017, 151, 163.

17. Ashori, A.; Bioresour. Technol. 2008, 99, 4661.

18. Ochi, S.; Composites, Part A 2006, 37, 1879.

19. Shah, A. A.; Hasan, F.; Hameed, A.; Ahmed, S.; Biotechnol. Adv. 2008, $26,246$. 
20. Sionkowska, A.; Wisniewski, M.; Kaczmarek, H.; Skopinska, J.; Chevallier, P.; Mantovani, D.; Lazare, S.; Tokarev, V.; Appl. Surf. Sci. 2006, 253, 1970.

21. Haroun, A. A.; J. Appl. Polym. Sci. 2009, 115, 3230.

22. Oromiehie, A. R.; Lari, T. T.; Rabiee, A.; J. Appl. Polym. Sci. 2013, 127, 1128.

23. Reesha, K. V; Panda, S. K.; Bindu, J.; Varghese, T. O.; Int. J. Biol. Macromol. 2015, 79, 934.

24. Zahra, S.; Abbas, S. S.; Mahsa, M.-T.; Mohsen, N.; Waste Manage. 2010, 30, 396

25. Dascălu, M. C.; Vasile, C.; Silvestre, C.; Pascu, M.; Eur. Polym. J. 2005, $41,1391$.

26. Thomson, R. C.; Yaszemski, M. J.; Powers, J. M.; Mikos, A. G.; Biomaterials 1998, 19, 1935.

27. Liu, H.; Webster, T. J.; Int. J. Nanomedicine 2010, 5, 299.

28. Boutinguiza, M.; Pou, J.; Comesaña, R.; Lusquiños, F.; de Carlos, A.; León, B.; Mater. Sci. Eng., C 2012, 32, 478.

29. Montero, P.; Gomez-Guillen, M. C.; J. Food Sci. 2000, 65, 434.

30. ASTM D 638-14 Standard Test Method for Tensile Properties of Plastics, 2004, p 1 .

31. ASTM D570-98 Standard Test Method for Water Absorption of Plastics, 2004, p. 25.

32. Norma G160-12, 2009 In Society; West Conshohocken, P., ed.; 2009. Vol. 03, p 3.

33. Schmidt, M. M.; Dornelles, R. C. P.; Mello, R. O.; Kubota, E. H.; Mazutti, M. A.; Kempka, A. P.; Demiate, I. M.; Int. Food Res. J. 2016, 23,913 .

34. Antonio, V.; Ricardo, I. P.; Sotelo, C. G.; Mar. Drugs 2017, 15, 131.
35. Venkatesan, J.; Kim, S. K.; Materials (Basel) 2010, 3, 4761

36. Coelho, T. M.; Nogueira, E. S.; Steimacher, A.; Medina, A. N.; Weinand, W. R.; Lima, W. M.; Baesso, M. L.; Bento, A. C.; J. Appl. Phys. 2006, 100.

37. Castiello, D.; Chiellini, E.; Cinelli, P.; D’Antone, S.; Puccini, M.; Salvadori, M.; Seggiani, M.; J. Appl. Polym. Sci. 2009, 114, 3827.

38. Sadighzadeh, A.; Azimzadeh Asiabi, P.; Ramazani, A.; Ghoranneviss, M.; Salar Elahi, A.; J. Inorg. Organomet. Polym. Mater. 2015, 25, 1448.

39. Pietrucha, K.; Int. J. Biol. Macromol. 2015, 80, 732.

40. Sionkowska, A.; Kozłowska, J.; Skorupska, M.; Michalska, M.; Int. J. Biol. Macromol. 2015, 80, 605.

41. Guzzi Plepis, A. M.; Goissis, G.; Das-Gupta, D. K.; Polym. Eng. 1996, 3,24 .

42. Sankar, S.; Sekar, S.; Mohan, R.; Rani, S.; Sundaraseelan, J.; Sastry, T. P.; Int. J. Biol. Macromol. 2008, 42, 6.

43. Valenzuela-Rojo, D. V.; López-Cervantes, J.; Sánchez-Machado, D. I. Em Seaweed Biomaterials, 2018, cap. 4

44. Tonhi, E.; Plepis, A. M. de G.; Quim. Nova 2002, 25, 6.

45. Peres, A. M.; Pires, R. R.; Oréfice, R. L.; Carbohydr. Polym. 2016, 136, 210 .

46. Bama, P.; Vijayalakshimi, M.; Jayasimman, R.; Kalaichelvan, P. T.; Deccaraman, M.; Sankaranarayanan, S.; Int. J. Pharm. Pharm. Sci. 2010, 2, 133 .

47. Jakubowicz, I.; Polym. Degrad. Stab. 2003, 80, 39

48. Martucci, J. F.; Ruseckaite, R. A.; J. Appl. Polym. Sci. 2009, 112.

49. Arcana, I. M.; Sulaeman, A.; Pandiangan, K. D.; Handoko, A.; Ledyastuti, M.; Polym. Int. 2006, 55, 435. 